\title{
Identification of copy number variations and common deletion polymorphisms in cattle
}

\author{
Joon Seol Bae', Hyun Sub Cheong², Lyoung Hyo Kim², Suk NamGung², Tae Joon Park', Ji-Yong Chun', \\ Jason Yongha Kim¹, Charisse Flerida A Pasaje ${ }^{1}$, Jin Sol Lee ${ }^{1}$, Hyoung Doo Shin 1,2*
}

\begin{abstract}
Background: Recently, the discovery of copy number variation (CNV) led researchers to think that there are more variations of genomic DNA than initially believed. Moreover, a certain CNV region has been found to be associated with the onset of diseases. Therefore, CNV is now known as an important genomic variation in biological mechanisms. However, most CNV studies have only involved the human genome. The study of CNV involving other animals, including cattle, is severely lacking.

Results: In our study of cattle, we used Illumina BovineSNP50 BeadChip (54,001 markers) to obtain each marker's signal intensity (Log R ratio) and allelic intensity (B allele frequency), which led to our discovery of 855 bovine CNVs from 265 cows. For these animals, the average number of CNVs was 3.2, average size was $149.8 \mathrm{~kb}$, and median size was $171.5 \mathrm{~kb}$. Taking into consideration some overlapping regions among the identified bovine CNVs, 368 unique CNV regions were detected. Among them, there were 76 common CNVRs with > 1\% CNV frequency. Together, these CNVRs contained 538 genes. Heritability errors of 156 bovine pedigrees and comparative pairwise analyses were analyzed to detect 448 common deletion polymorphisms. Identified variations in this study were successfully validated using visual examination of the genoplot image, Mendelian inconsistency, another CNV identification program, and quantitative PCR.
\end{abstract}

Conclusions: In this study, we describe a map of bovine CNVs and provide important resources for future bovine genome research. This result will contribute to animal breeding and protection from diseases with the aid of genomic information.

\section{Background}

Cattle have been important to human culture for over 8,000 years as an agricultural means, for transportation, and as a supply of meat and milk [1]. In recent years, studies have been conducted that attempt to increase the productivity of meat and marbling grades by utilizing genetic factors [2-5], and the results of these studies have been deemed economically significant. The bovine genome is made up of 29 autosomes and sex chromosomes with a genome size estimated to be around 2.87 Gbp. Because of the economic importance of cows, the Bovine Genome Sequencing and Analysis Consortium has decoded bovine whole-genomic information (Bovine Genome Project) and has reported that a minimum of 22,000 genes are included in the cattle genome [6].

\footnotetext{
* Correspondence: hdshin@sogang.ac.kr

'Laboratory of Genomic Diversity, Department of Life Science, Sogang

University, Shinsu-dong, Mapo-gu, Seoul 121-742, Republic of Korea
}

These findings show that bovine genome analysis is becoming increasingly popular.

Copy number variation (CNV) is an event in which a large DNA fragment $(>1 \mathrm{~kb})$ is duplicated or deleted. According to recent studies, structural variations that include $\mathrm{CNV}$ affect gene expression and are related to the onset of many diseases [7-10]. However, these studies usually focused only on the human genome, while studies of other animals such as cows have been minimal. Although a recent study found $25 \mathrm{CNVs}$ in three Holsteins by array comparative genomic hybridization (aCGH) [11], an analysis that uses many bovine samples to find a way to utilize the cow's genomic character economically is yet to be conducted. Moreover, CNVs in genomes exist in low frequency; therefore, it is advisable to analyze many samples in order to find common $\mathrm{CNV}$ regions for analysis with various phenotypes. In the case of animal genomes, Skinner and colleagues have 
reported a detailed molecular cytogenetic map as a result of a comparative genomics study in chicken and Pekin duck using a CGH microarray [12], and Griffin and colleagues also reported 16 interspecific CNVs between chicken and turkey [13]. As in the case of cattle genome, a recent paper reported $25 \mathrm{CNVs}$ discovered using array comparative genomic hybridization (aCGH) with 3 Holsteins as samples [11]. However, in order to investigate the association between various economically beneficial phenotypes and CNVs, more bovine CNVs would need to be discovered.

Two platforms for identifying individual CNVs, aCGH and a single nucleotide polymorphism (SNP) genotyping array, have been widely used. In the case of the former, signal intensity was varied when comparing the reference and target with the dye-swap method [8]. Regarding the latter, clustered pool references, signal intensity, and allelic intensity (B allele frequency) were used to identify CNV [14-16]. The SNP genotyping array has the advantage of performing both whole-genome SNP association analysis and CNV analysis [14]. This platform also provides various information including Mendelian inconsistency (heritability error), deviation from Hardy-Weinberg equilibrium (HWE), and genotype missing rate. Recent studies have used this advantage to identify common deletion polymorphisms efficiently [17-19]. In addition, accurate and efficient algorithms have also been developed recently that discover CNV not only by means of signal intensity, but also through B allele frequency and family information, and these methods are widely used [15,20-24]. In order to detect reliable CNVs, we studied multiple factors including signal intensity, B allele frequency, marker distance, and population frequency of the B allele (PFB) using PennCNV $[9,24,25]$.

In this study, we examined 256 bovine samples using a SNP genotyping array to discover genomic variations that include individual CNVs and common deletion polymorphisms from the whole cattle genome. Our goal is to provide genomic variation information that could be used to find economical genetic traits in cattle.

\section{Results}

In this study, we used Illumina BovineSNP50 BeadChip and PennCNV to identify CNVs in cattle (Additional file
1 ; table s1). One sample contained an average of 3.2 CNVs with an average length and a median size of $149.8 \mathrm{~kb}$ and $118.7 \mathrm{~kb}$ (Table 1 ), respectively. After all CNVs were aggregated for the CNV region (CNVR), 368 CNVRs were identified (Additional file 2; table s2). The average number of CNVs per sample was 1.4 , with an average length and median size of $171.5 \mathrm{~kb}$ and $128.3 \mathrm{~kb}$, respectively. Furthermore, 76 CNVRs with > $1 \%$ frequency, 22 CNVRs with $>2.5 \%$ frequency, and 6 CNVRs with $>5 \%$ frequency were also inferred from this study. A total of 538 genes were included in the identified CNVR (Table 1). Common CNVRs with CNV frequency higher than $2.5 \%$ are listed in Table 2, with chr15:1836732-2039483 CNVR having the highest frequency (13.2\%) and chr17:75520590-76487768 CNVR having the highest number of genes. Figure 1 shows the map of CNVRs discovered from this study. We were also able to detect 368 CNVRs that were distributed evenly across the chromosomes. Among them, we found 99 CNVRs with only gain (duplication), 310 with only loss (deletion), and 22 CNVRs (freq. > 2.5\%) that share common values.

The sizes of the identified CNVs ranged from 50 200 $\mathrm{kb}$, with a few outliers having a size of $250 \mathrm{~kb}$, and most chromosomes had more loss than gain (Additional file 3; figure s1, s2). Figure 2 shows the result of visual examination by genoplot image within chr15:18367322039483 and validation by qPCR. Samples representing hemizygous deletion (color: cyan; copy number: $1 \times$ ) of the first marker had the same intensity position up to the fourth marker, consecutively (Figure 2c). The real copy numbers of samples by qPCR around the third marker (marker name: Hapmap24310-BTA-162764; position: 1959352) were matched with expected copy numbers on the genoplot image (Figure 2b). In addition, most identified CNVs using CNVPartition overlapped with the CNVs detected using PennCNV (94\%) (Additional file 4 ; table s3). To identify common deletion polymorphisms, we used two methods: a heritability error analysis called genotype transmission error, and pairwise analysis. In order to analyze heritability error, 156 sire and steer family sets were used. These sets had parent-child heritability frequency that was equal to or greater than $99.6 \%$ and a confirmed parent-child

Table 1 Summary of identified copy number variations in Bos taurus coreanae $(n=265)$

\begin{tabular}{|c|c|c|c|c|c|c|c|c|c|c|c|}
\hline & $\begin{array}{c}\text { Total } \\
\text { number }\end{array}$ & $\begin{array}{l}\text { Average no. } \\
\text { of CNVs per } \\
\text { sample }\end{array}$ & $\begin{array}{l}\text { Average } \\
\text { size of } \\
\text { CNVs (kb) }\end{array}$ & $\begin{array}{c}\text { Median } \\
\text { size of } \\
\text { CNVs (kb) }\end{array}$ & $\begin{array}{c}\text { No. } \\
\text { of } \\
\text { Gain }\end{array}$ & $\begin{array}{l}\text { No. } \\
\text { of } \\
\text { Loss }\end{array}$ & $\begin{array}{l}\text { Ratio } \\
\text { (Loss/ } \\
\text { Gain) }\end{array}$ & $\begin{array}{c}\text { No. of } \\
\text { common } \\
\text { CNVs (freq. } \\
>1 \% \text { ) }\end{array}$ & $\begin{array}{c}\text { No. of } \\
\text { common CNVs } \\
\text { (freq. }>2.5 \% \text { ) }\end{array}$ & $\begin{array}{c}\text { No. of } \\
\text { common } \\
\text { CNVs (freq. } \\
>5 \% \text { ) }\end{array}$ & Genes \\
\hline $\begin{array}{c}\text { Individual } \\
\text { CNV }\end{array}$ & 855 & 3.2 & 149.8 & 118.7 & 221 & 634 & 2.9 & - & & & - \\
\hline $\begin{array}{l}\text { CNV } \\
\text { region }\end{array}$ & 368 & 1.4 & 171.5 & 128.3 & - & - & - & 76 & 22 & 6 & 538 \\
\hline
\end{tabular}


Table 2 Summary of common copy number variation regions in Bos taurus coreanae (freq. $>\mathbf{2 . 5 \%}$ )

\begin{tabular}{|c|c|c|c|c|c|}
\hline CNV region & $\begin{array}{l}\text { Length } \\
\text { (bp) }\end{array}$ & $\begin{array}{l}\text { No. of } \\
\text { CNVs }\end{array}$ & Frequency & $\begin{array}{l}\text { No. of } \\
\text { genes }\end{array}$ & Genes \\
\hline chr15:1836732-2039483 & 202,751 & 35 & 0.132 & 0 & \\
\hline chr5:11483310-11889745 & 406,435 & 28 & 0.106 & 0 & \\
\hline chr17:75520590-76487768 & 967,178 & 24 & 0.091 & 21 & $\begin{array}{c}\text { ARVCF, C17H220rf25, CDC45L, CLDN5, COMT, DGCR14, DGCR2, DGCR8, } \\
\text { FAM128B, LOC515651, MED15, PI4KA, RANBP1, SEPT5, SERPIND1, SLC25A1, } \\
\text { SNAP29, THAP7, TUBA3E, TXNRD2, UFD1L }\end{array}$ \\
\hline chr17:15002419-15372017 & 369,598 & 22 & 0.083 & 1 & SMARCA5 \\
\hline chr13:54700988-55222116 & 521,128 & 16 & 0.060 & 12 & $\begin{array}{c}\text { ARFGAP1, ARFRP1, C13H20ORF11, C13H20orf149, C13H20orf195, DIDO1, EEF1A2, } \\
\text { RTEL, SLC17A9, STMN3, TNFRSF6B, ZGPAT }\end{array}$ \\
\hline chr20:31559229-31832019 & 272,790 & 15 & 0.057 & 0 & \\
\hline chr3:36163190-36338393 & 175,203 & 13 & 0.049 & 2 & CSFI,GSTM3 \\
\hline chr4:10009287-10665698 & 656,411 & 13 & 0.049 & 3 & GATADI, LOC524650, MGC148329 \\
\hline chr5:102164053-102261488 & 97,435 & 10 & 0.038 & 2 & GUCY2C, PLBD1 \\
\hline chr19:12442436-12611334 & 168,898 & 10 & 0.038 & 0 & \\
\hline chr11:109101259-109497448 & 396,189 & 9 & 0.034 & 10 & $\begin{array}{c}\text { C11H9ORF142, C8G, CLIC3, EDF1, KIAA1984, MAMDC4, PARF, PHPT1, PTGDS, } \\
\text { TMEM141 }\end{array}$ \\
\hline chr18:10398490-10604602 & 206,112 & 9 & 0.034 & 1 & MGC140224 \\
\hline chr18:48593919-48725107 & 131,188 & 9 & 0.034 & 6 & EID2, MED29, RPS16, SUPT5H, TIMM50, ZFP36 \\
\hline chr20:46603190-46767627 & 164,437 & 9 & 0.034 & 0 & \\
\hline chr25:42346692-42719563 & 372,871 & 9 & 0.034 & 3 & CARD11, CHST12, LFNG \\
\hline chr1:40050487-40150878 & 100,391 & 8 & 0.030 & 0 & \\
\hline chr5:123127110-123347200 & 220,090 & 8 & 0.030 & 1 & PPARA \\
\hline chr7:4650135-5033417 & 383,282 & 8 & 0.030 & 11 & $\begin{array}{c}\text { CIST1, IFI30, ISYNA1, JUND, LRRC25, LSM4, MPV17L2, PGPEP1, PIK3R2, RAB3A, } \\
\text { SSBP4 }\end{array}$ \\
\hline chr17:24499559-24727631 & 228,072 & 8 & 0.030 & 0 & \\
\hline chr20:51402609-51459233 & 56,624 & 8 & 0.030 & 0 & \\
\hline chr6:56495043-56634157 & 139,114 & 7 & 0.026 & 0 & \\
\hline chr10:90756777-90887327 & 130,550 & 7 & 0.026 & 0 & \\
\hline
\end{tabular}

relationship. To calculate for heritability error, we used Illumina BeadStudio 3.2 software and detected a total of 990 errors. From that, we selected 320 parent-child heritability errors whose frequency was equal to or greater than $3 \%$ for the purpose of identifying common deletion polymorphisms. Figure 3 displays a number of identified common deletion polymorphisms for each frequency of father (sire) and child (steer) heritability error. When the number of heritability errors increased, the number of distributed markers decreased. However, there were more common deletion polymorphisms (71.4\%) observed for markers with higher heritability frequency (>10\%) than for those $(60.6 \%)$ with low heritability frequency $(<10 \%)$. Following this method, we found a total of 351 common deletion polymorphisms. Moreover, we were also able to detect 192 common deletion polymorphisms by pairwise comparison, analyzing between reference and target samples. Merging the identified common deletion polymorphisms from the two methods, we were able to identify a total of 448 common deletion polymorphisms, with 95 of them common to both methods (Additional file 5; table s4). Common deletion polymorphisms found in this study were distributed from chromosomes 1 to 29 quite evenly, with chromosome 2 having the most and chromosome 25 having the least (Additional file 3; figure s3). In order to quantitatively measure for common deletion polymorphisms, we performed qPCR around ARSBFGL-NGS-24778 in chromosome 2 (Position: 61648422) (Figure 4e). As a result, we were able to confirm that the expected copy number changes in each sample, based on visual examination of the genoplot image, existed at those sites (Figure 4f).

\section{Discussion}

Cattle are important resources for humans as providers of meat and milk and as labor power for agriculture. Lately, interest and research concerning bovine genetic resources are increasing, as evident in the completion of the Bovine Genome Project. However, current studies on bovine $\mathrm{CNV}$, which is an important area of genetic variation along with SNPs, are very minimal. In the past few years, CNVs have been studied extensively in the human genome, and many human CNVs have been discovered and reported to the DGV (Database of Genomic Variants; http://projects.tcag.ca/variation). Recently, identifying how CNVs in the human genome affect 


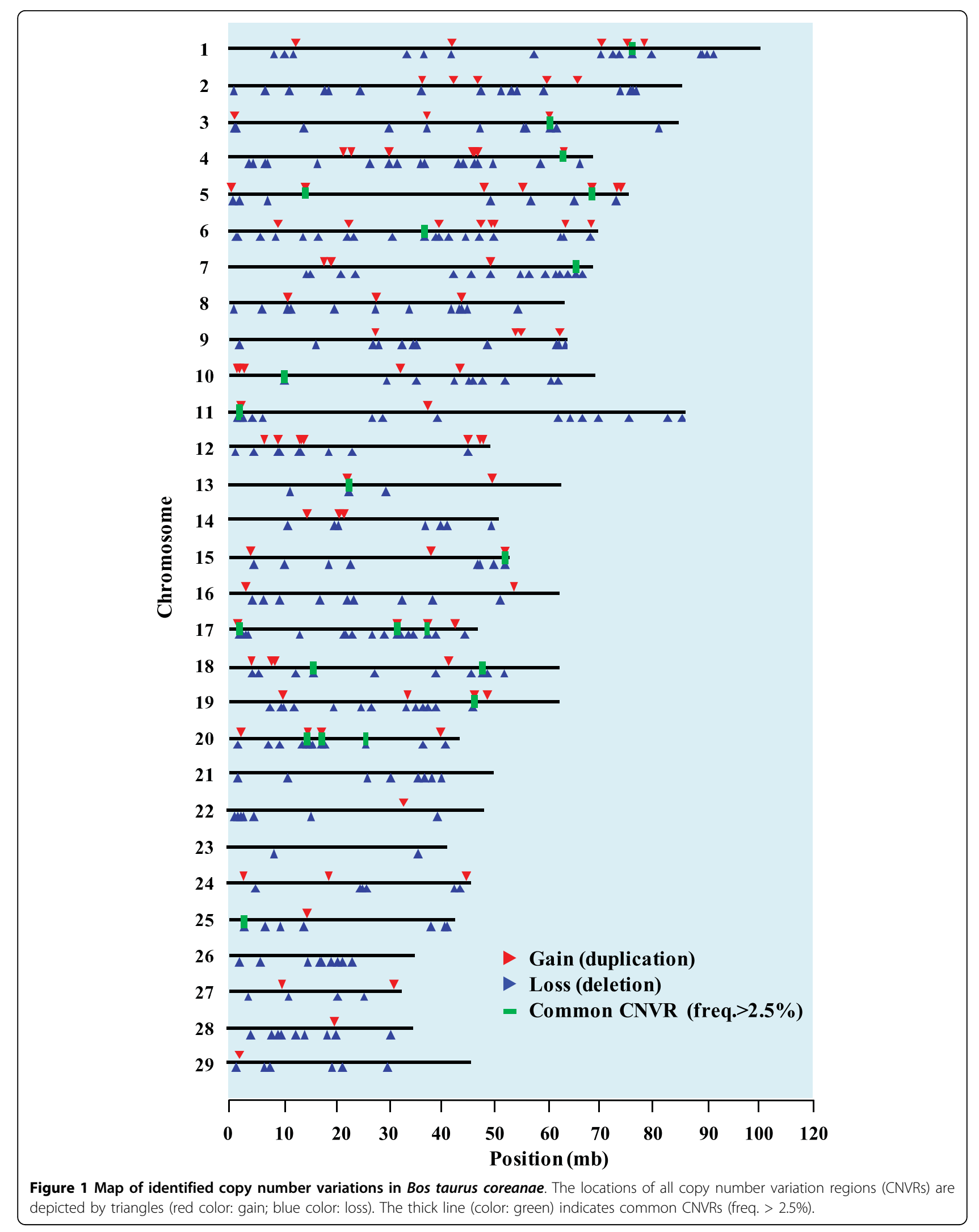




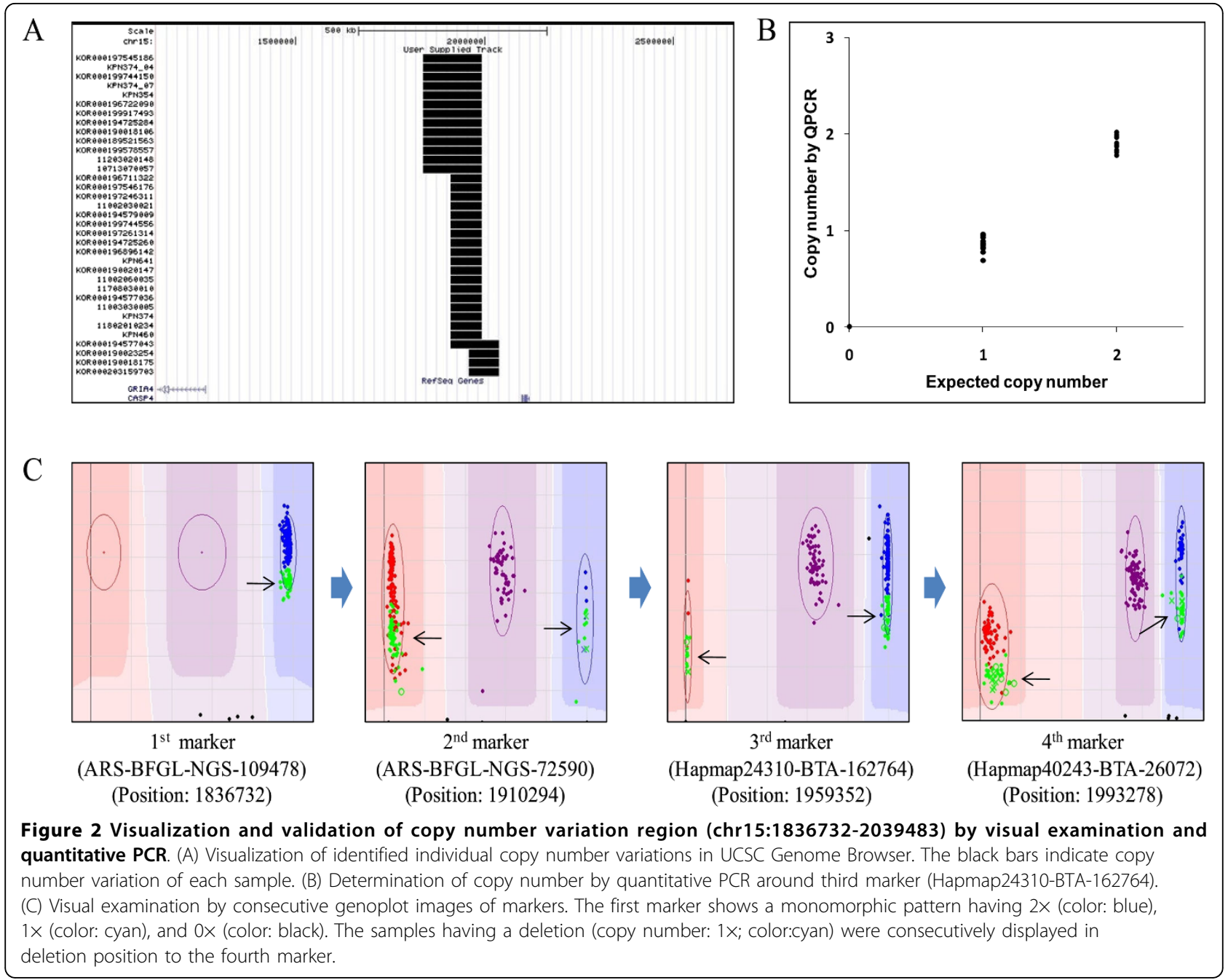

various given phenotypes, including disease susceptibility, has become a major focus for researchers [26]. In the animal genome, certain economically useful phenotypes undoubtedly exist. Based on the findings from this study, future research might be able to examine the genetic effects of $\mathrm{CNV}$ on various economic traits, including beef quality. In order to facilitate such studies, CNVs discovered from each animal should be entered in a database similar to that of the human genome. Until now, most CNV researchers have run their association analysis using CNV genotyping according to differences in signal intensity alone. However, $\mathrm{CNV}$ is usually linked to nearby SNPs. Just lately, CNV and SNP combined analysis has been used. The main advantage of this method is that it can analyze signal intensity and allelic differences simultaneously. In other words, it is possible to do multi-allelic CNV/SNP genotyping on CNVs containing multiple SNP markers. Our previous study reported that after discovering and genotyping multi-allelic CNV markers in the deletion region of the human genome, CNV/SNP combined analysis provided more reliable association results than using SNP or CNV genotyping alone [27].

In this study, we identified 855 bovine CNVs and 368 CNVRs. To apply the findings of this study, the common CNVRs we were able to identify will be useful in analyzing certain relationships among phenotypes. For example, a common CNVR provides important genome information for discovering genes related to beef grade and meat productivity. CNV identification was performed using Illumina BeadChip and algorithm made from Btau_4.0. If UMD3 bovine genome assembly was used, more accurate CNV identification result would have been expected. Identified CNVRs in this study were validated using visual examination, in which comparison with the results of CNVPartition and qPCR was performed. In Figure s4 (additional file 6), we demonstrate how this value changes in a region where copy number change appears in a schematic way. For a normal copy number $(2 \times)$, two homozygous genotypes 


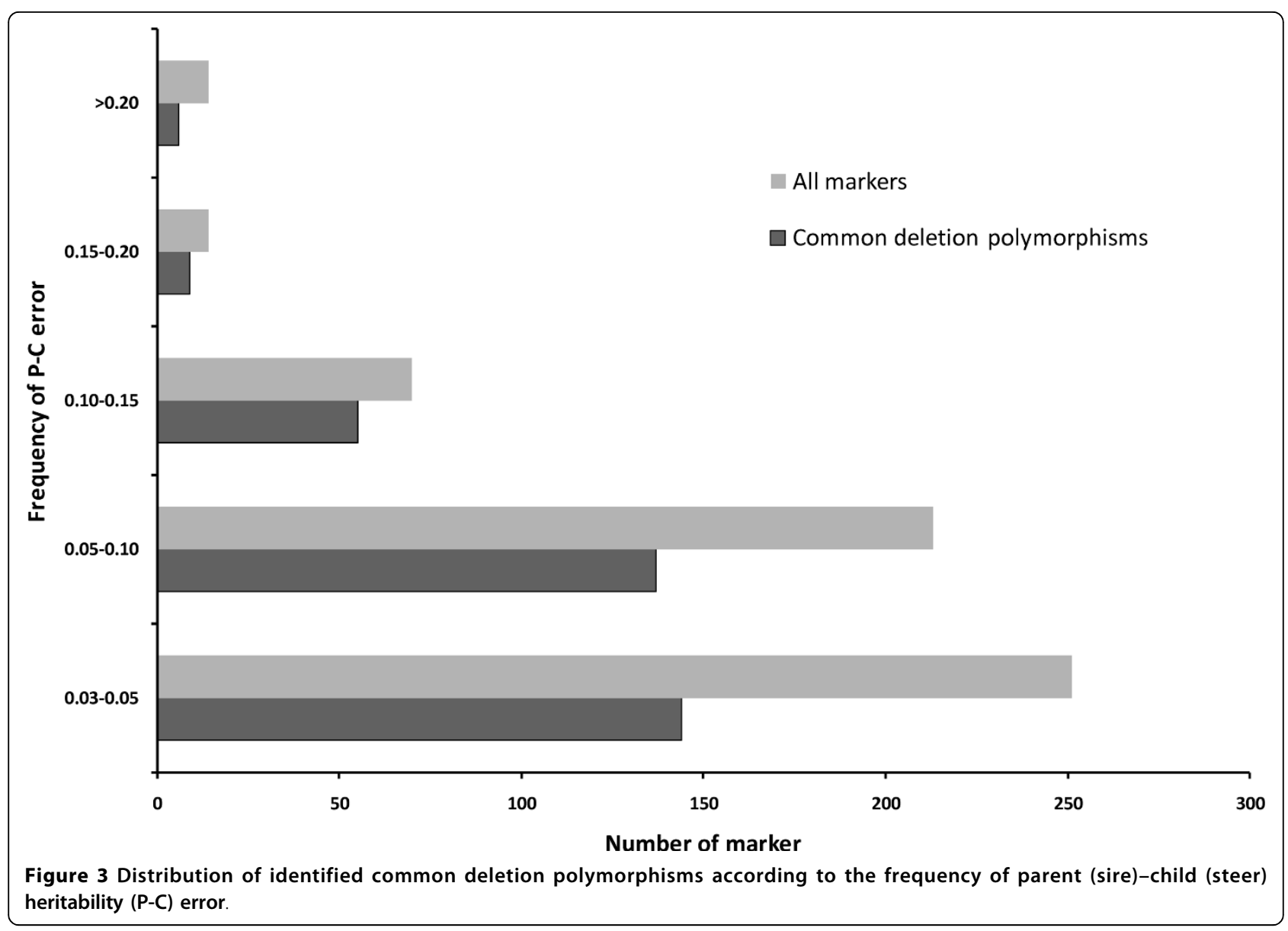

(A/A and $\mathrm{B} / \mathrm{B}$ ) and one heterozygous genotype (A/B) appear on one genoplot image. On the other hand, a heterozygous genotype $(\mathrm{A} / \mathrm{B})$, which only emerges in a normal copy number $(2 \times)$, disappeared in a region where deletion $(1 \times)$ occurred. This explains why only two lines (A/A and B/B) were evident. If gain (copy number: $3 \times$ ) appears in the genoplot image, there would have been four lines $(\mathrm{A} / \mathrm{A} / \mathrm{A}, \mathrm{A} / \mathrm{A} / \mathrm{B}, \mathrm{A} / \mathrm{B} / \mathrm{B}$, and $\mathrm{B} / \mathrm{B} / \mathrm{B})$. If $B$ allelic frequency and signal intensity were simultaneously used to discover $\mathrm{CNV}$ in the case of deletion and duplication, the identification would be more accurate. To date, the study by Liu et al. is the only one regarding bovine CNV identification [11], as far as we know, and it reported $25 \mathrm{CNVs}$ from three Holstein using array CGH (Btau 3.0). To compare with previous $\mathrm{CNV}$ data on cattle, we converted the coordinates of the 25 bovine CNVs with Btau4.0 using the LiftOver tool in the UCSC database. However, only one CNV overlapped with our results. Although it is not easy to decipher this discrepancy, different breeds of cattle and/or a smaller number of animals was used in the previous study.

$\mathrm{CNV}$ is defined as a DNA fragment higher than $1 \mathrm{~kb}$, and copy number variation smaller than $1 \mathrm{~kb}$ is called an indel. Recently, it has been reported that the latest discoveries of CNV sizes were much smaller than the previous results due to the advances made in the chip platform $[17,28]$. Zhang and colleagues have mentioned that the cutoff value of $1 \mathrm{~kb}$ is completely arbitrary, and they suggest choosing an average exon size ( 100 bp) in defining CNV [26]. Also, Venter and Watson demonstrated that CNV size distributions show a marked enrichment ranging from 300 to $350 \mathrm{bp}$ using wholegenome shotgun sequencing and massively parallel DNA sequencing methods $[29,30]$. Although we used a $50 \mathrm{~K}$ chip for this study, high-resolution methods used for human genome study such as high-density chip or next generation sequencing should be applied to animal genomes, including cattle. For future studies determining the exact CNV boundary, this current study would be valuable in that it could serve as a preliminary report providing whole-genome $\mathrm{CNV}$ distribution resources regarding the cattle genome.

Indels could affect phenotype and gene expression dosage such as CNV, and may need to be studied further. We developed a method to efficiently discover common deletion polymorphisms among indels, and 


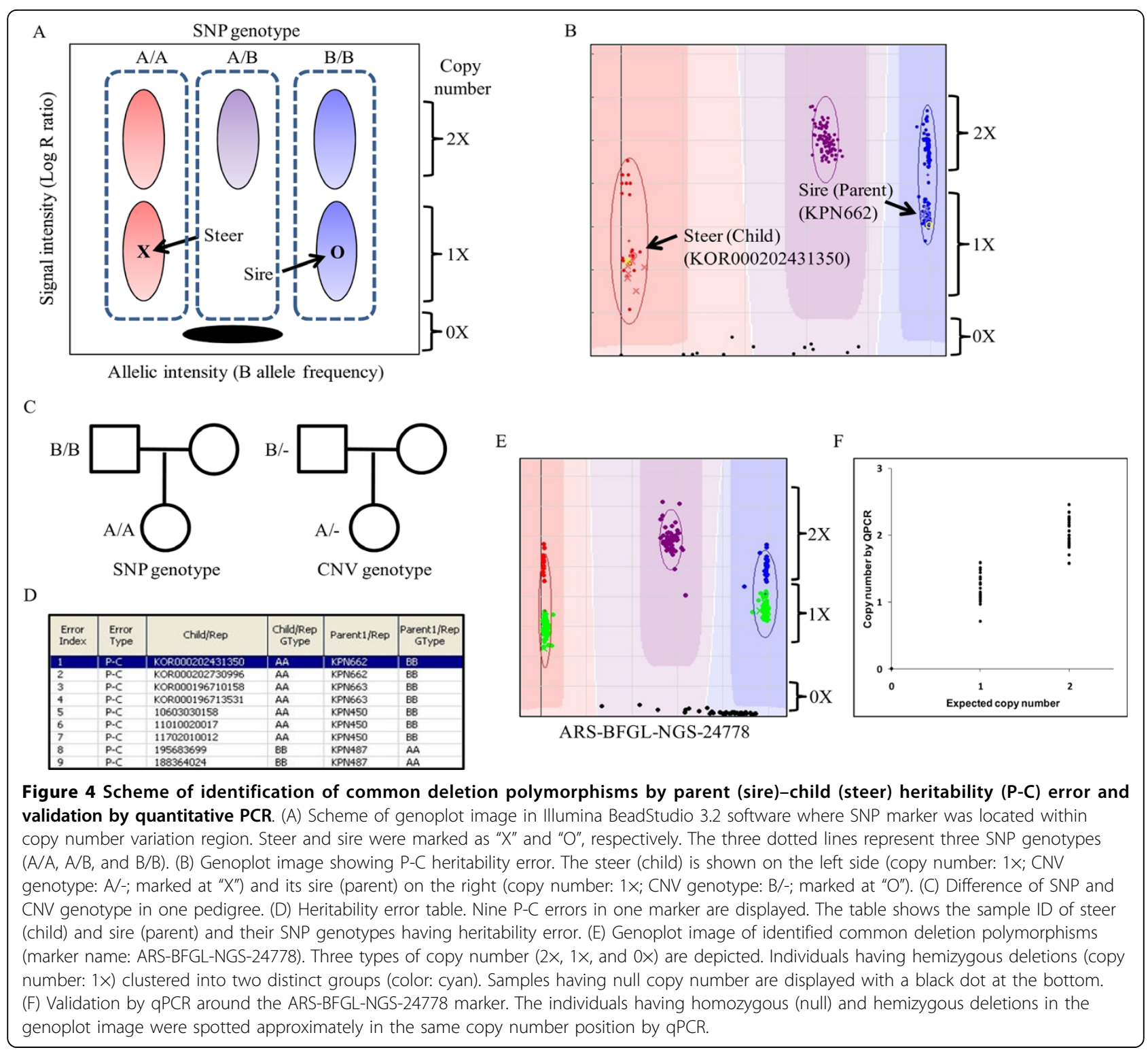

subsequently identified 448 common deletion polymorphisms in this study. Figure 4 schematically shows the cause of sire and steer heritability error when an SNP marker exists within the CNVR. If a deletion occurs on an allele, subsequently it will lead to heritability errors since if a sample exists on the $1 \times$ position, the SNP genotype becomes A/A (steer) and B/B (sire), as exhibited in Figure 4c. Using this heritability error, investigation of a region with frequent $\mathrm{P}-\mathrm{C}$ errors can increase the accuracy and efficiency of identifying the variants. This method is much more effective than the one previously used [27].

Gene ontology (GO) analysis can provide insight into the functional enrichment of CNVs. For this reason, we ran GO analysis using DAVID http://david.abcc.ncifcrf.gov provided by the National Institute of Allergy and Infectious Diseases (NIAID) and NIH [31]. As a result, we found that genes significantly enriched in the identified bovine CNVs include the cytoplasm, intracellular part, cytoplasmic part, and intracellular organelle. Since CNV can influence regions within $500 \mathrm{~kb}$, we performed additional enrichment analysis. The gene functions enriched in nearby genes include the multicellular organismal process, regulation of biological quality, and cell morphogenesis (Table 3). This analysis provides estimated results of expected functions, so additional study of function consequences between actual phenotypes should be carried out.

This study aims to provide genomic resources required for analyzing what economic impact phenotypes and bovine CNVs can bring to the table. In the 
Table 3 Gene ontology (GO) categories significantly overrepresented in bovine copy number variations

\begin{tabular}{|c|c|c|c|}
\hline Group & GO Term & Count & $P$-value \\
\hline \multirow[t]{34}{*}{ Gene } & cytoplasm & 73 & $7.62 \mathrm{E}-10$ \\
\hline & intracellular part & 95 & 7.74E-09 \\
\hline & cytoplasmic part & 52 & $9.79 \mathrm{E}-08$ \\
\hline & intracellular organelle & 81 & $3.74 \mathrm{E}-07$ \\
\hline & organelle & 81 & $3.74 \mathrm{E}-07$ \\
\hline & intracellular & 100 & $3.76 \mathrm{E}-07$ \\
\hline & developmental process & 31 & $2.14 \mathrm{E}-06$ \\
\hline & $\begin{array}{l}\text { intracellular membrane-bound } \\
\text { organelle }\end{array}$ & 70 & 3.87E-06 \\
\hline & membrane-bound organelle & 70 & 3.93E-06 \\
\hline & binding & 130 & $5.64 \mathrm{E}-06$ \\
\hline & cell differentiation & 22 & $1.70 \mathrm{E}-05$ \\
\hline & cellular developmental process & 22 & $1.70 \mathrm{E}-05$ \\
\hline & $\begin{array}{l}\text { negative regulation of cellular } \\
\text { process }\end{array}$ & 16 & 2.27E-05 \\
\hline & $\begin{array}{l}\text { multicellular organismal } \\
\text { development }\end{array}$ & 22 & 4.24E-05 \\
\hline & regulation of apoptosis & 12 & 4.28E-05 \\
\hline & $\begin{array}{l}\text { regulation of programmed cell } \\
\text { death }\end{array}$ & 12 & 4.87E-05 \\
\hline & $\begin{array}{l}\text { negative regulation of biological } \\
\text { process }\end{array}$ & 16 & $5.02 \mathrm{E}-05$ \\
\hline & intracellular organelle part & 40 & 5.89E-05 \\
\hline & cell development & 17 & $6.14 \mathrm{E}-05$ \\
\hline & organelle part & 40 & $6.36 \mathrm{E}-05$ \\
\hline & protein binding & 61 & 8.41E-05 \\
\hline & apoptosis & 14 & $1.06 \mathrm{E}-04$ \\
\hline & programmed cell death & 14 & 1.17E-04 \\
\hline & biological regulation & 47 & $1.72 \mathrm{E}-04$ \\
\hline & organelle membrane & 22 & $1.90 \mathrm{E}-04$ \\
\hline & regulation of cellular process & 41 & 2.02E-04 \\
\hline & death & 14 & 2.37E-04 \\
\hline & cell death & 14 & 2.37E-04 \\
\hline & regulation of biological process & 43 & 2.62E-04 \\
\hline & DNA replication & 8 & 2.67E-04 \\
\hline & multicellular organismal process & 25 & $6.73 \mathrm{E}-04$ \\
\hline & calmodulin binding & 6 & 7.07E-04 \\
\hline & anatomical structure development & 17 & 8.08E-04 \\
\hline & cell cycle & 12 & 9.23E-04 \\
\hline \multirow[t]{5}{*}{ Nearby gene } & multicellular organismal process & 19 & $6.90 \mathrm{E}-07$ \\
\hline & regulation of biological quality & 11 & 2.98E-05 \\
\hline & cell morphogenesis & 6 & 5.63E-04 \\
\hline & cellular structure morphogenesis & 6 & 5.63E-04 \\
\hline & $\begin{array}{l}\text { cellular morphogenesis during } \\
\text { differentiation }\end{array}$ & 4 & 7.67E-04 \\
\hline
\end{tabular}

case of the human genome, the map of identified CNVs presented by Redon and colleagues [8] is now used as important information in association studies on various diseases including autism, inflammatory autoimmune disorders, idiopathic learning disability, lung cancer, systemic lupus erythematosus, and schizophrenia. In addition, follow-up studies for high-resolution $\mathrm{CNV}$ mapping have been actively occurring. However, CNVs related to economically useful phenotypes are yet to be thoroughly researched, so we expect the results of this study to provide meaningful genomic variation information for related research.

Future studies should include additional analysis for accurate size estimation of bovine CNVs and common deletion polymorphisms found in this study, followed by an association analysis of bovine phenotypes.

\section{Conclusions}

In summary, we have identified 855 new CNVs and 448 common deletion polymorphisms in Bos taurus coreanae. These variations were successfully validated using visual examination, Mendelian inconsistency, CNVPartition, and qPCR. Here, we report the map of bovine CNVs. We expect this result will provide important resources for future bovine genome research.

\section{Methods}

\section{Subjects and Illumina Infinium II assay}

The cattle (Bos taurus coreanae) genomic DNA samples were obtained from 248 steers produced from 17 sires $(n=265)$. All blood samples were collected from the Seosan Livestock Institute (NLRI). We used the Illumina BovineSNP50 BeadChip containing 54,001 markers that uniformly span the entire bovine genome (Illumina, Inc., USA). Those markers were obtained by Illumina's Genome Analyzer, a next-generation sequencing system, and publicly available sources including a bovine reference genome (Btau 4.0) and Bovine HapMap Consortium data set. The mean and median of spacing in this BeadChip was $51.5 \mathrm{~kb}$ and $37.3 \mathrm{~kb}$, respectively. Using Illumina's Infinium II assay, the genotyped data for a total of 54,001 markers were collected for identification of bovine CNVs. The assay procedure used has been described in our previous study [27]. We incorporated single-base extension (SBE) which uses a single probe sequence that is $50 \mathrm{bp}$ long and is designed to hybridize immediately adjacent to the SNP query site. Briefly, each sample was whole-genome amplified, fragmented, precipitated, and re-suspended in an appropriate hybridization buffer. Denatured samples were hybridized on the BovineSNP50 BeadChip for a minimum of $16 \mathrm{~h}$ at 48 degree. After completion of the assay, the BeadChips were scanned with a two-color, confocal BeadArray reader. Scanned image intensities were loaded directly into Illumina's BeadStudio 3.2 software. When normalization was completed, the clustering process was performed to assess cluster position for each marker and to determine individual genotypes. The overall SNP genotyping call rate was $99.57 \%$, which indicated that high-quality data was extracted for this study. 


\section{Identification of bovine copy number variations}

All signal intensity (log $R$ ratio: LRR) and allelic intensity (B allele frequency: BAF) ratios of samples were reported using Illumina BeadStudio 3.2 software. We used high quality samples with a standard deviation (SD) of LRR < 0.30 to assess the noise of the intensity signal. To identify individual CNVs, we used the PennCNV, which incorporates multiple factors including LRR, BAF, marker distance, and population frequency of the $B$ allele $[15,32]$. Because bovine has 29 autosomal chromosomes, we used an alternative program argument; the "-lastchr 29" in the "-detect" argument to be specific CNV regions (CNVRs) were aggregated from identified CNVs by considering each other's overlapping regions. For verification purposes of the identified CNVs, CNVpartition program with default criteria (Illumina Inc., USA) was initially used to identify CNVs after which, results were compared with those that were obtained using PennCNV.

\section{Identification of common deletion polymorphisms}

If a deletion is positioned on the SNP marker, deviation from Hardy-Weinberg equilibrium, Mendelian inconsistency (heritability error) in a family (Figure 4), and a high missing genotype rate particularly appear. To identify common deletion polymorphisms in this study, we used heritability error of the genotype for both sire (parent) and steer (child). In our previous study, we found that common deletion polymorphisms have a unique pattern in the BeadStudio genoplot [27]. We designated these common deletion polymorphisms to multi-allelic $\mathrm{CNV}$ markers because they had six distinct genotypes (A/A, A/ $\mathrm{B}, \mathrm{B} / \mathrm{B}, \mathrm{A} /-, \mathrm{B} /-$, and $-/-)$ according to the differences in the copy numbers and allelic intensities [33]. Recently, other research has also described the two-dimensional feature of each marker in an SNP genotyping array $[9,16,34]$. To identify common deletion polymorphisms, we selected candidate markers with a frequency of sire and steer heritability error (P-C error) $>3 \%$. After we checked the heritability of 156 sire and steer sets, heritability error frequency was calculated using BeadStudio 3.2. Among the candidate markers, we found common deletion polymorphisms representing six distinct cluster images by visual inspection. In addition, we used the pairwise method for identifying hidden common deletion polymorphisms. After selecting a high-quality reference sample, we constructed paired sets representing intensity differences between target and reference samples using the paired sample editor in BeadStudio 3.2. The range of inspection of the marker was both $\log _{2}\left(R_{\text {sub }} / R_{\text {ref }}\right) \leq-1.5$ and $\log _{2}\left(R_{\text {sub }} / R_{\text {ref }}\right) \geq 1.5$ (Additional file 3; figure $s 5$ ).

\section{Validation by quantitative PCR}

To validate the existence of both the $\mathrm{CNV}$ region and common deletion polymorphisms, we performed
TaqMan real-time PCR on an ABI Prism 7900 sequence detection system (Applied Biosystems, Foster City, CA). Specific probes were generated by Primer Express 2.0 (Additional file 6; table s5). The basic transcription factor 3 (BTF3) gene, which served as an internal standard, was co-amplified with the marker. Amplification reactions (10 ul) were carried out in duplicate with $10 \mathrm{ng}$ of template DNA, 1× TaqMan Universal Master Mix buffer (Applied Biosystems), $900 \mathrm{nM}$ of each primer, and 250 $\mathrm{nM}$ of each fluorogenic probe. Thermal cycling was initiated with a 2-min incubation at 50 degrees followed by a denaturation step from $10 \mathrm{~min}$ at 95 degrees, to 40 cycles of $15 \mathrm{sec}$ at 95 degrees, and lastly to $1 \mathrm{~min}$ at 60 degrees. Three replicate reactions were performed for primer pairs, and a comparative $C_{T}$ method was used to calculate the copy number [35] (Applied Biosystems user bulletin $\# 2[\mathrm{P} / \mathrm{N} 4303859]) . \Delta \mathrm{C}_{\mathrm{T}}$ was calculated by subtracting the BTF3 $\mathrm{C}_{\mathrm{T}}$ value from the sample $\mathrm{C}_{\mathrm{T}}$ value for each replicate. The average $C_{T}$ value for the three replicates was then calculated. In order to determine the $\Delta \Delta C_{\mathrm{T}}, \Delta \mathrm{C}_{\mathrm{T}}$ 's from all other samples were normalized. Finally, the copy number was given using the formula $2 \times 2^{-\Delta \Delta C T}$.

\section{Validation by visual examination of genoplot image}

Illumina BeadStudio 3.2 software provides visual genoplot images representing signal intensity (Y-axis) and allelic intensity (X-axis) simultaneously per marker. To validate the existence of both identified CNVRs and common deletion polymorphisms in this study, we visually inspected the consecutive changes in signal intensity and allelic intensity for each sample at each genoplot image using the above software.

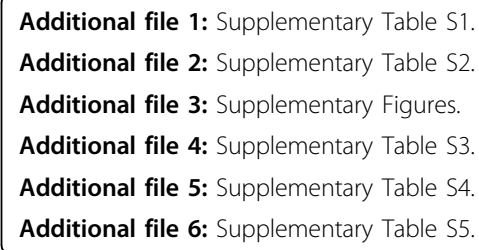

\section{Acknowledgements}

This study was supported by the Technology Development Program for Agriculture and Forestry, Ministry of Agriculture and Forestry, Republic of Korea. We thank Dr. Ki Wang (Department of Genetics, University of Pennsylvania, and Center for Applied Genomics, Children's Hospital of Philadelphia, Philadelphia, PA 19104, USA) for providing useful scripts for the PennCNV algorithm.

\section{Author details}

'Laboratory of Genomic Diversity, Department of Life Science, Sogang University, Shinsu-dong, Mapo-gu, Seoul 121-742, Republic of Korea. 2Department of Genetic Epidemiology, SNP Genetics, Inc., Room 1407, Complex B, WooLim Lion's Valley, 371-28, Gasan-Dong, Geumcheon-Gu, Seoul 153-801, Republic of Korea. 


\section{Authors' contributions}

J.S.B. performed microarray data analysis, produced the results and drafted the manuscript. H.S.C., L.H. K. and S. N. contributed to the preparation of samples and Infinium II assay. T.J.P., J.-Y.C. and J.S.L. provided technical assistance. J.Y.K. and C.F.A.P. have been involved in critically revising the manuscript for important intellectual content. H.D.S. contributed to the conception of the study and participated in the interpretation of the results and revision of the manuscript. All authors read and approved the final manuscript.

Received: 4 December 2009 Accepted: 9 April 2010 Published: 9 April 2010

\section{References}

1. Barendse W, Vaiman D, Kemp SJ, Sugimoto Y, Armitage SM, Williams JL, Sun HS, Eggen A, Agaba M, Aleyasin SA, et al: A medium-density genetic linkage map of the bovine genome. Mamm Genome 1997, 8(1):21-28.

2. Cheong HS, Yoon DH, Park BL, Kim LH, Bae JS, Namgoong S, Lee HW, Han CS, Kim JO, Cheong IC, et al: A single nucleotide polymorphism in CAPN1 associated with marbling score in Korean cattle. BMC Genet 2008, 9:33.

3. Cheong HS, Yoon DH, Kim LH, Park BL, Choi YH, Chung ER, Cho YM, Park EW, Cheong IC, Oh SJ, et al: Growth hormone-releasing hormone (GHRH) polymorphisms associated with carcass traits of meat in Korean cattle. BMC Genet 2006, 7:35.

4. Casas E, White SN, Riley DG, Smith TP, Brenneman RA, Olson TA, Johnson DD, Coleman SW, Bennett GL, Chase CC Jr: Assessment of single nucleotide polymorphisms in genes residing on chromosomes 14 and 29 for association with carcass composition traits in Bos indicus cattle. $J$ Anim Sci 2005, 83(1):13-19.

5. Gan QF, Zhang LP, Li JY, Hou GY, Li HD, Gao X, Ren HY, Chen JB, Xu SZ: Association analysis of thyroglobulin gene variants with carcass and meat quality traits in beef cattle. J Appl Genet 2008, 49(3):251-255.

6. Elsik CG, Tellam RL, Worley KC, Gibbs RA, Muzny DM, Weinstock GM, Adelson DL, Eichler EE, Elnitski L, Guigo R, et al: The genome sequence of taurine cattle: a window to ruminant biology and evolution. Science 2009, 324(5926):522-528

7. Scherer SW, Lee C, Birney E, Altshuler DM, Eichler EE, Carter NP, Hurles ME, Feuk $\mathrm{L}$ : Challenges and standards in integrating surveys of structural variation. Nat Genet 2007, 39(7 Suppl):S7-15,

8. Redon R, Ishikawa S, Fitch KR, Feuk L, Perry GH, Andrews TD, Fiegler $H$, Shapero MH, Carson AR, Chen W, et al: Global variation in copy number in the human genome. Nature 2006, 444(7118):444-454.

9. Glessner JT, Wang K, Cai G, Korvatska O, Kim CE, Wood S, Zhang H, Estes A, Brune CW, Bradfield JP, et al: Autism genome-wide copy number variation reveals ubiquitin and neuronal genes. Nature 2009, 459(7246):569-573.

10. Lee C, Morton CC: Structural genomic variation and personalized medicine. N Engl J Med 2008, 358(7):740-741.

11. Liu GE, Van Tassel CP, Sonstegard TS, Li RW, Alexander LJ, Keele JW, Matukumalli LK, Smith TP, Gasbarre LC: Detection of germline and somatic copy number variations in cattle. Dev Biol (Basel) 2008, 132:231-237.

12. Griffin DK, Robertson LB, Tempest HG, Vignal A, Fillon V, Crooijmans RP, Groenen MA, Deryusheva S, Gaginskaya E, Carre W, et al: Whole genome comparative studies between chicken and turkey and their implications for avian genome evolution. BMC Genomics 2008, 9:168.

13. Skinner BM, Robertson LB, Tempest HG, Langley EJ, loannou D, Fowler KE, Crooijmans RP, Hall AD, Griffin DK, Volker M: Comparative genomics in chicken and Pekin duck using FISH mapping and microarray analysis. BMC Genomics 2009, 10:357.

14. Peiffer DA, Le JM, Steemers FJ, Chang W, Jenniges T, Garcia F, Haden K, Li J, Shaw CA, Belmont J, et al: High-resolution genomic profiling of chromosomal aberrations using Infinium whole-genome genotyping. Genome Res 2006, 16(9):1136-1148.

15. Wang K, Li M, Hadley D, Liu R, Glessner J, Grant SF, Hakonarson H, Bucan M: PennCNV: an integrated hidden Markov model designed for highresolution copy number variation detection in whole-genome SNP genotyping data. Genome Res 2007, 17(11):1665-1674.

16. Yau C, Holmes CC: CNV discovery using SNP genotyping arrays. Cytogenet Genome Res 2008, 123(1-4):307-312
17. McCarroll SA, Kuruvilla FG, Korn JM, Cawley S, Nemesh J, Wysoker A Shapero MH, de Bakker PI, Maller JB, Kirby A, et al: Integrated detection and population-genetic analysis of SNPs and copy number variation. Nat Genet 2008, 40(10):1166-1174.

18. McCarroll SA, Hadnott TN, Perry GH, Sabeti PC, Zody MC, Barrett JC, Dallaire S, Gabriel SB, Lee C, Daly MJ, et al: Common deletion polymorphisms in the human genome. Nat Genet 2006, 38(1):86-92.

19. Greenway SC, Pereira AC, Lin JC, DePalma SR, Israel SJ, Mesquita SM, Ergul E, Conta JH, Korn JM, McCarroll SA, et al: De novo copy number variants identify new genes and loci in isolated sporadic tetralogy of Fallot. Nat Genet 2009, 41(8):931-935.

20. Colella S, Yau C, Taylor JM, Mirza G, Butler H, Clouston P, Bassett AS, Seller A, Holmes CC, Ragoussis J: QuantiSNP: an Objective Bayes HiddenMarkov Model to detect and accurately map copy number variation using SNP genotyping data. Nucleic Acids Res 2007, 35(6):2013-2025.

21. Cronin S, Blauw HM, Veldink JH, van Es MA, Ophoff RA, Bradley DG, Berg van den LH, Hardiman O: Analysis of genome-wide copy number variation in Irish and Dutch ALS populations. Hum Mol Genet 2008, 17(21):3392-3398.

22. Attiyeh EF, Diskin SJ, Attiyeh MA, Mosse YP, Hou C, Jackson EM, Kim C, Glessner J, Hakonarson H, Biegel JA, et al: Genomic copy number determination in cancer cells from single nucleotide polymorphism microarrays based on quantitative genotyping corrected for aneuploidy. Genome Res 2009, 19(2):276-283.

23. Itsara A, Cooper GM, Baker C, Girirajan S, Li J, Absher D, Krauss RM, Myers RM, Ridker PM, Chasman DI, et al: Population analysis of large copy number variants and hotspots of human genetic disease. Am J Hum Genet 2009, 84(2):148-161.

24. Henrichsen CN, Vinckenbosch N, Zollner S, Chaignat E, Pradervand S, Schutz F, Ruedi M, Kaessmann H, Reymond A: Segmental copy number variation shapes tissue transcriptomes. Nat Genet 2009, 41(4):424-429.

25. Yang S, Wang K, Gregory B, Berrettini W, Wang LS, Hakonarson H, Bucan M: Genomic landscape of a three-generation pedigree segregating affective disorder. PLoS One 2009, 4(2):e4474.

26. Zhang F, Gu W, Hurles ME, Lupski JR: Copy number variation in human health, disease, and evolution. Annu Rev Genomics Hum Genet 2009, 10:451-481.

27. Bae JS, Cheong HS, Kim JO, Lee SO, Kim EM, Lee HW, Kim S, Kim JW, Cui T, Inoue I, et al: Identification of SNP markers for common CNV regions and association analysis of risk of subarachnoid aneurysmal hemorrhage in Japanese population. Biochem Biophys Res Commun 2008, 373(4):593-596.

28. Perry GH, Ben-Dor A, Tsalenko A, Sampas N, Rodriguez-Revenga L, Tran CW, Scheffer A, Steinfeld I, Tsang P, Yamada NA, et al: The fine-scale and complex architecture of human copy-number variation. Am J Hum Genet 2008, 82(3):685-695.

29. Wheeler DA, Srinivasan M, Egholm M, Shen Y, Chen L, McGuire A, He W, Chen YJ, Makhijani V, Roth GT, et al: The complete genome of an individual by massively parallel DNA sequencing. Nature 2008, 452(7189):872-876

30. Levy S, Sutton G, Ng PC, Feuk L, Halpern AL, Walenz BP, Axelrod N, Huang J, Kirkness EF, Denisov G, et al: The diploid genome sequence of an individual human. PLOS Biol 2007, 5(10):e254.

31. Dennis G Jr, Sherman BT, Hosack DA, Yang J, Gao W, Lane HC, Lempicki RA DAVID: Database for Annotation, Visualization, and Integrated Discovery. Genome Biol 2003, 4(5):P3.

32. Wang K, Chen Z, Tadesse MG, Glessner J, Grant SF, Hakonarson H, Bucan M, Li M: Modeling genetic inheritance of copy number variations. Nucleic Acids Res 2008, 36(21):e138.

33. Park M, Kim DJ, Kim KJ, Hong CB, Kim YJ, Cheong HS, Shin HD, Lee EJ, Kim HN, Chung HW, et al: Genetic associations of common deletion polymorphisms in families with Avellino corneal dystrophy. Biochem Biophys Res Commun 2009, 387(4):688-693.

34. Winchester L, Newbury DF, Monaco AP, Ragoussis J: Detection, breakpoint identification and detailed characterisation of a CNV at the FRA16D site using SNP assays. Cytogenet Genome Res 2008, 123(1-4):322-332.

35. Bodin L, Beaune PH, Loriot MA: Determination of Cytochrome P450 2D6 (CYP2D6) Gene Copy Number by Real-Time Quantitative PCR. J Biomed Biotechnol 2005, 2005(3):248-253.

doi:10.1186/1471-2164-11-232

Cite this article as: Bae et al:: Identification of copy number variations and common deletion polymorphisms in cattle. BMC Genomics 2010 $11: 232$. 